\title{
INFLUÊNCIA DA PRESSÃO, TEMPERATURA E PRÉ-TRATAMENTOS NA SECAGEM A VÁCUO DE CENOURA E ABÓBORA ${ }^{1}$
}

\author{
Aroldo ARÉVALO-PINEDO ${ }^{2, *}$, Fernanda Elizabeth Xidieh MURR ${ }^{3}$
}

\section{RESUMO}

O presente trabalho visou estudar experimentalmente a cinética de secagem a vácuo de cenoura e abóbora "in natura" e pré-tratadas por branqueamento e congelamento. Os ensaios experimentais foram conduzidos em um secador a vácuo, nas pressões de 5 , 15 e $25 \mathrm{kPa}$ e temperaturas de 50,60 e $70^{\circ} \mathrm{C}$. Estudou-se a influência da pressão e temperatura assim como os pré-tratamentos adotados sobre a cinética de secagem. A análise do efeito dos pré-tratamentos e dos parâmetros pressão e temperatura sobre a velocidade de secagem revelou que os melhores valores foram obtidos com a temperatura de $70^{\circ} \mathrm{C}$ e pressão de $5 \mathrm{kPa}$ para as amostras prétratadas por congelamento. Quanto ao tipo de matéria-prima utilizado, a abóbora apresentou maiores velocidades de secagem que a cenoura, independentemente do tratamento recebido e da condição de secagem utilizada. As curvas experimentais de secagem foram ajustadas ao modelo difusional de Fick para uma placa plana infinita.

Palavras-chave: secagem a vácuo, cenoura, abóbora, difusividade efetiva.

\section{SUMMARY}

INFLUENCE OF PRESSURE AND TEMPERATURE AND PRE-TREATMENTS IN THE CARROT AND PUMPKIN VACUUM DRYING. In this work it was studied experimentally the kinetics of drying of carrot and pumpkin under vacuum drying in nature and pretreatment by freezing and bleaching. The experimental runs were driven in a dryer under vacuum, at pressures of 5,15 and $25 \mathrm{kPa}$ and temperatures of 50,60 and $70^{\circ} \mathrm{C}$. The influences on the drying kinetics of the pressures and temperature were studied, as well as the effect of adopting pre-treatment. It was observed that the best values were obtained at the temperature of $70^{\circ} \mathrm{C}$ and pressure of $5 \mathrm{kPa}$ for the samples pretreatment by freezing. As concerns to the raw material employed, pumpkin presented higher drying speeds than the one shown by carrot, independently of the treatment received and of the operational condition of drying. The experimental curves of drying were adjusted to the difusional model of Fick for an infinite slab.

Keywords: vacuum drying, carrot, pumpkin, effective diffusivity.

\section{1 - INTRODUÇÃO}

A difusividade efetiva de umidade é uma importante propriedade de transporte, sendo útil na análise das operações de processamento de produtos alimentícios, como a secagem. Porém, devido à complexa composição e à estrutura física dos alimentos, não são conseguidas estimativas precisas desta propriedade, sendo assim necessárias medidas experimentais, como observado em vários trabalhos encontrados na literatura.

A secagem é empregada visando diversas finalidades. Para os produtos agrícolas e alimentícios, é empregada principalmente na preservação, permitindo também o transporte e armazenamento sem refrigeração. A perda de massa que ocorre quando um alimento é seco diminui consideravelmente os custos de transporte e manuseio. Dentro dos vários métodos de secagem, a secagem a vácuo é utilizada por ser um método intermediário entre a secagem tradicional e a liofilização, pois permite trabalhar a pressões baixas com temperaturas moderadas (menores que $100^{\circ} \mathrm{C}$ ), obtendo-se maiores taxas de evaporação da umidade e um produto final de melhor qualidade se comparado com a secagem tradicional com ar quente (KOMPANY et al., 1990; KROKIDA, ZOGZAS, MAUROLIS, 1997).

A aplicação de pré-tratamentos como o branqueamento e o congelamento à matéria-prima antes da secagem possibilitam modificar a estrutura natural da matéria-prima para melhorar a transferência de umidade e, portanto, aumentar

\footnotetext{
${ }^{1}$ Recebido para publicação em 20/02/2003. Aceito para publicação em 02/08/2005 (001072).

${ }^{2}$ Curso de Engenharia de Alimentos - UFT, Av. NS-15, ALC NO-14, CEP 77176-000, Palmas /TO. E-mail: aroldo@uft.edu.br.

${ }^{3}$ Faculdade de Engenharia de Alimentos - UNICAMP - Caixa Postal 6121 CEP 13083-970, Campinas/SP - Brasil.

*A quem a correspondência deve ser enviada.
}

a velocidade de secagem do produto como comprovam os trabalhos de KOMPANY et al. (1990).

O objetivo deste trabalho foi estudar os efeitos da pressão, temperaturas e os pré-tratamentos na secagem a vácuo de cenoura e abóbora.

\section{2 - MATERIAL E MÉTODOS}

\section{1 - Matéria-prima}

Para realização do presente trabalho, cenoura (Daucus carota) e abóbora (Cucúrbita máxima) foram utilizadas, as quais foram adquiridas do comércio local de Campinas. A composição química da cenoura utilizada foi de $90,45 \%$ de umidade, 0,55\% de proteína e 2,29\% para açúcares totais de $2,29 \%$, sendo que a abóbora apresentou $94,30 \%$ de umidade, $0,60 \%$ de proteínas e 3,02\% de açúcares totais.

\section{2 - Equipamento de secagem}

O secador (Figura 2.1) utilizado para a realização dos experimentos foi descrito e desenvolvido por ARÉVALO-PINEDO (2003). Consta de uma câmara de secagem construída de chapa de ferro de $4 \mathrm{~cm}$ de espessura com dimensões de 45 mm de largura, altura e profundidade e tampa de acrílico de $9 \mathrm{~mm}$ de espessura. As condições de vácuo dentro da câmara foram mantidas por uma bomba de vácuo e monitoradas através de um manômetro.

O sistema de aquecimento é constituído por uma placa de aço inoxidável, com dimensões de $10 \mathrm{~cm}$ de largura por $25 \mathrm{~cm}$ de comprimento, aquecida por uma resistência elétrica de $250 \mathrm{~W}$ que está ligada a um regulador automático de temperatura. 


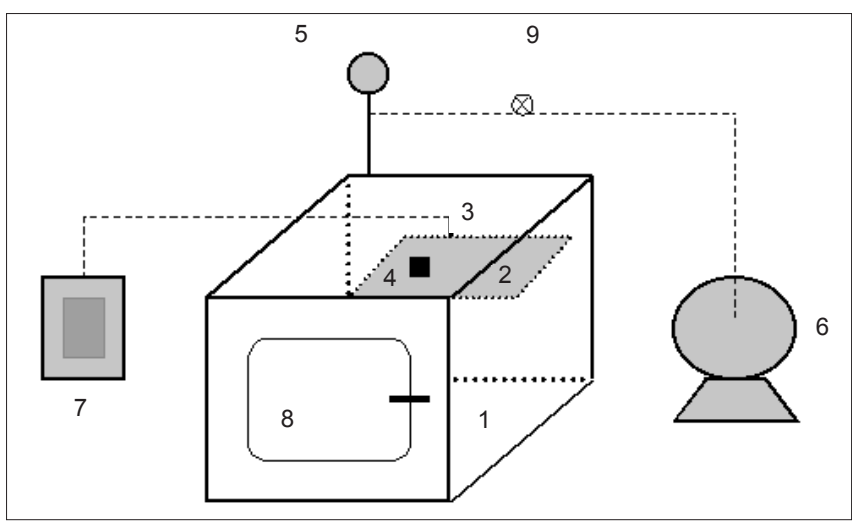

FIGURA 2.1 - Secador a vácuo: 1. Câmara de secagem; 2. Placa de aço inox aquecida por resistência elétrica; 3 . Termopar tipo PT-100; 4. Amostra; 5. Vacuômetro; 6. Bomba de vácuo; 7. Regulador automático de temperatura; 8. Porta da câmara de acrílico, 9. válvula

\section{3 - Secagem}

A matéria-prima foi lavada em água corrente, com a finalidade de retirar as impurezas. As amostras utilizadas na secagem foram cortadas em formato de lâminas com dimensões aproximadas de: $5 \mathrm{~mm}, 40 \mathrm{~mm}$ e $20 \mathrm{~mm}$ de espessura; comprimento e de largura respectivamente. A massa inicial das amostras foi de aproximadamente 5,50 a 6 g. A medida da massa das amostras durante a secagem foi determinada com uma balança analítica, com precisão de 0,001 g. Durante os ensaios experimentais, utilizaram-se amostras "in natura" e as pré-tratadas por branqueamento e congelamento.

\subsection{1 - Branqueamento e congelamento}

$\mathrm{O}$ branqueamento foi efetuado com água à temperatura de $80^{\circ} \mathrm{C}$ à pressão atmosférica, por 4 minutos. Ao término dos 4 minutos, as amostras foram resfriadas em água fria e o excesso de água superficial foi escorrido.

O congelamento das amostras foi realizado num "freezer" comercial com recirculação de ar à temperatura de $-15^{\circ} \mathrm{C}$ por 5 horas. As amostras preparadas foram colocadas dentro de uma embalagem de papel alumínio para evitar a formação de blocos de gelo na superfície. Após congelamento, as amostras foram descongeladas à temperatura ambiente antes do início do ensaio por tempo aproximado de 15 a 20 minutos.

\subsection{2 - Estimativa da difusividade efetiva}

A análise do processo de secagem, os ajustes das curvas experimentais e o cálculo da difusividade efetiva da amostra foram realizados com base na segunda lei de Fick, assumindo a forma geométrica de uma placa plana infinita, onde a transferência interna de umidade durante a secagem é apenas em uma direção:

$$
\frac{\partial \mathrm{X}}{\partial t}=\frac{\partial \mathrm{X}}{\partial \gamma}\left(D_{e f} \frac{\partial \mathrm{X}}{\partial \gamma}\right)
$$

Considerando: a secagem ocorrendo apenas por uma das fases; a difusividade efetiva $D_{e f}$ constante; a umidade inicial $\mathrm{X}_{\mathrm{o}}$ uniformemente distribuída no interior do produto; a resistência externa ao transporte de massa desprezível; a umidade na superfície constante e sendo igual à umidade de equilíbrio $\mathrm{X}_{\mathrm{e}}$ do produto; a umidade de ar de secagem constante e o encolhimento desprezível. A média volumétrica da solução da Equação (2.1), obtida por BROOKER et al., 1974 e CRANK, 1975, é

$$
\frac{X-X_{e}}{X_{o}-X_{e}}=\frac{8}{\pi^{2}} \sum_{n=0}^{\infty} \frac{1}{(2 n+1)^{2}} \exp \left[\frac{-(2 n+1)^{2} \pi^{2} D_{e f} t}{4 L^{2}}\right]
$$

Com as seguintes condições:

$$
\begin{aligned}
& \text { Inicial: } \quad X=X_{\mathrm{o}} \quad \text { em } \quad \mathrm{t}=0, \quad 0 \leq \mathrm{y} \leq \mathrm{L} \\
& \text { Contorno: } X=X_{e} \quad \text { em } \quad \mathrm{t} \geq 0, \quad \mathrm{y}=\mathrm{L} \\
& \frac{\partial X}{\partial t}=0 \quad \text { em } \quad \mathrm{t} \geq 0, \quad \mathrm{y}=0
\end{aligned}
$$

Em que: $X=$ umidade média volumétrica $(\mathrm{g} / \mathrm{g}) ; X_{e}=$ umidade de equilíbrio $(\mathrm{g} / \mathrm{g}) ; X_{o}=$ umidade inicial $(\mathrm{g} / \mathrm{g})$; $\left(X-X_{e}\right)\left(X_{o}-X_{e}\right)=$ razão de umidade decimal, base seca, adimensional; $D_{e f}=$ difusividade efetiva $\left(\mathrm{m}^{2} / \mathrm{s}\right) ; \mathrm{t}=$ tempo (s) e L = espessura (m).

\section{3 - RESULTADOS E DISCUSSÃo}

\section{1 - Efeito da temperatura de secagem na cenoura e abóbora}

Para avaliar o efeito da temperatura e da pressão na cinética de secagem da cenoura e abóbora pré-tratadas por congelamento e branqueamento e in natura foram construídos os gráficos das Figuras 3.1 para cenoura e 3.2 para abóbora. Na Figura 3.1 tem-se a curva de secagem de amostras de cenoura pré-tratada por congelamento e branqueamento e as in natura ou sem tratamento, obtida à temperatura de 50,60 e $70^{\circ} \mathrm{C}$, na pressão $5 \mathrm{kPa}$.

Através destas curvas de secagem, pode-se observar que a maior parte do processo transcorre dentro do período de velocidade decrescente. Nota-se também que a temperatura de secagem exerce influência sobre a velocidade de secagem em cada tipo de amostra estudada, sendo o tempo de secagem menor com o aumento da temperatura. Assim como a temperatura, a pressão também exerce influências na cinética de cada tipo de amostra estudada. O aumento da temperatura causa uma diminuição do tempo de secagem em todos os casos. Este tempo diminui ainda mais quando diminui a pressão de secagem.

Da Figura 3.2 observa-se que, tal como ocorrido nas amostras de cenoura, para um mesmo tempo de processo, quanto maior a temperatura de secagem, maior a perda de umidade das amostras de produto. As amostras de abóbora congeladas secas à temperatura de $70^{\circ} \mathrm{C}$ e pressão de $5 \mathrm{kPa}$ 


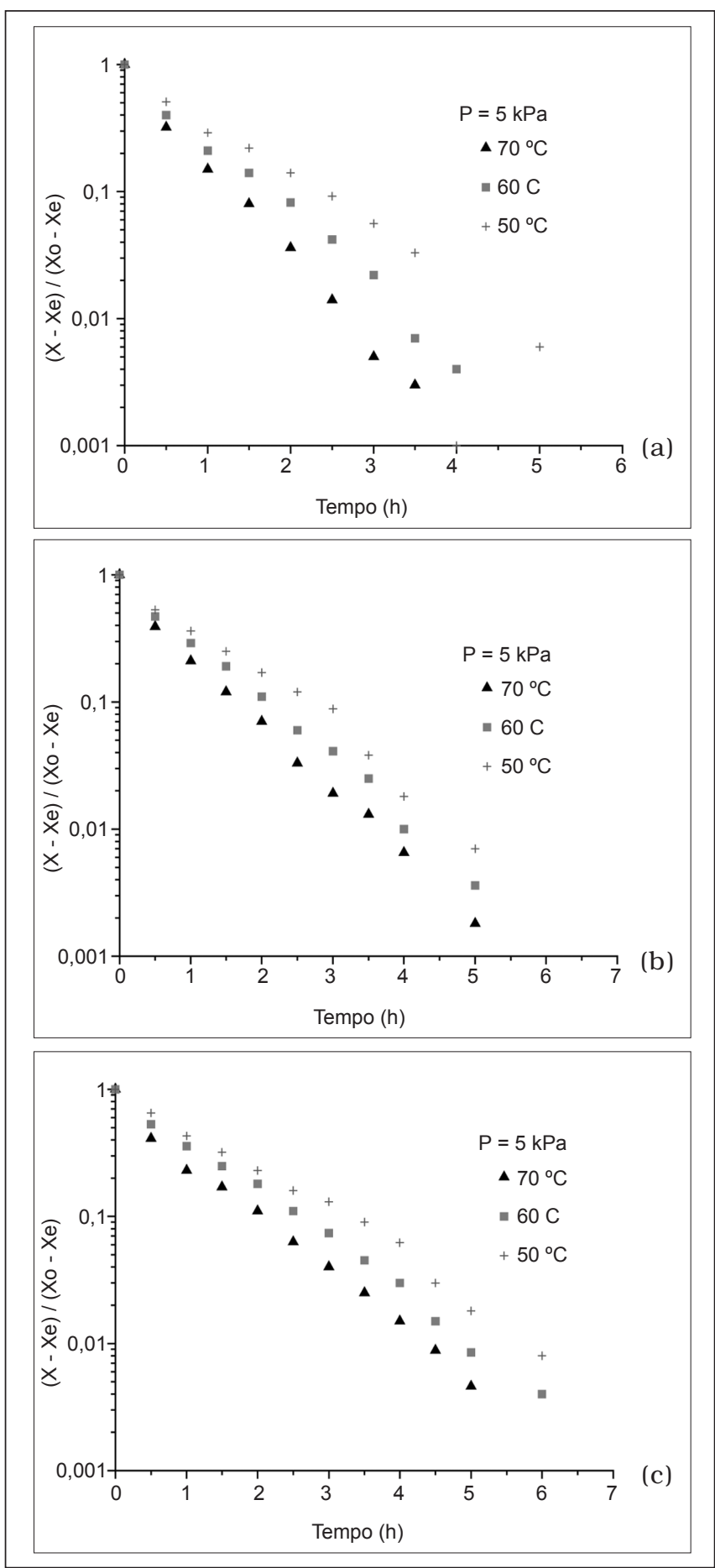

FIGURA 3.1 - Efeito da temperatura de secagem para secagem de cenoura: (a) congelada, (b) branqueada e (c) "in natura", à temperatura de 50,60 e $70{ }^{\circ} \mathrm{C}$ e pressão de $5 \mathrm{kPa}$

apresentaram melhores resultados, conseguindo-se maior velocidade de secagem. Inclusive é ligeiramente maior que a velocidade apresentada pela cenoura nestas mesmas condições. O tempo necessário para a secagem de abóbora congelada é de aproximadamente 2 horas sendo que para a cenoura é necessário um pouco mais de 2,5 horas. Segundo KOMPANY (1990), o tipo de matéria-prima também pode influenciar positivamente na velocidade de secagem.
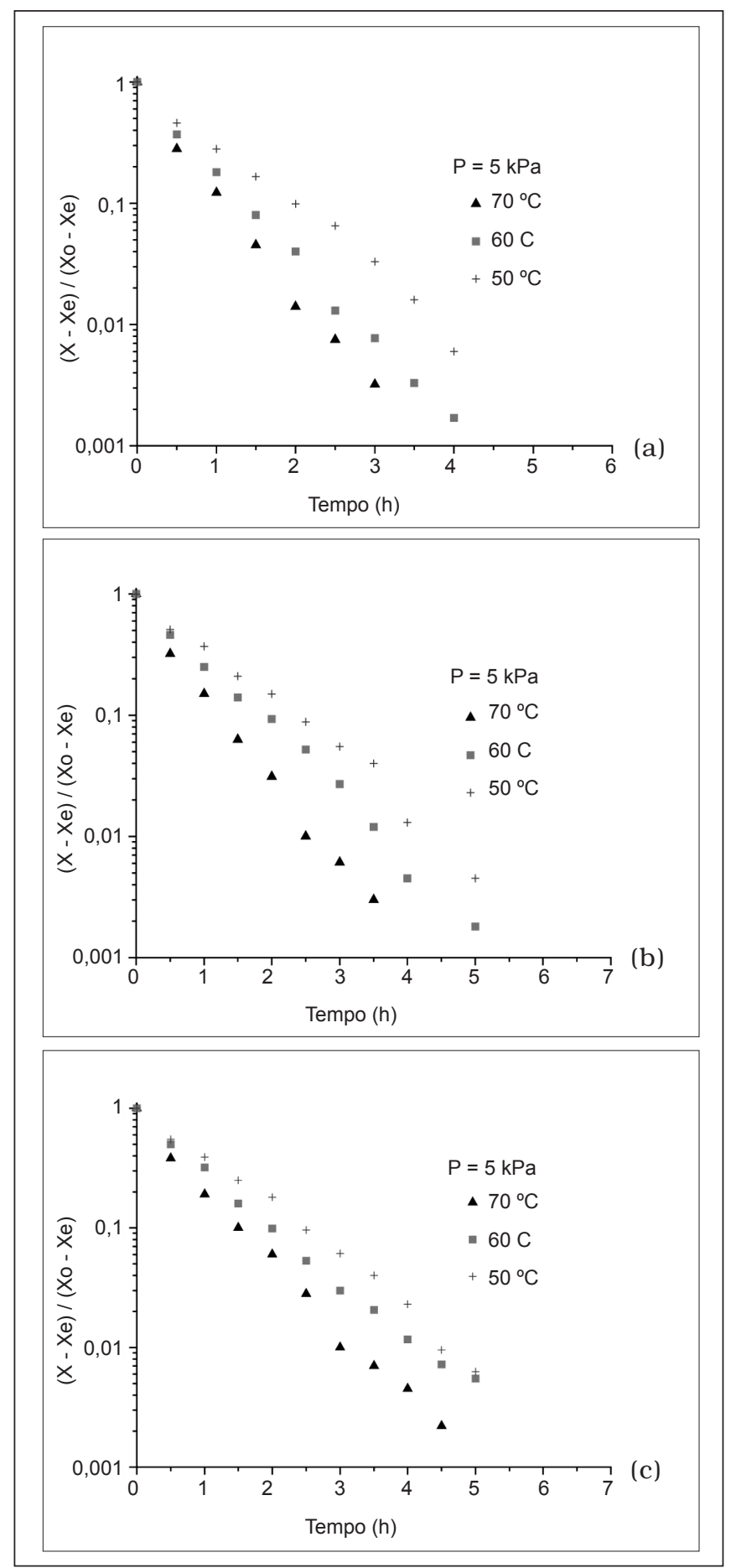

FIGURA 3.2 - Efeito da temperatura de secagem para abóbora:

(a) congelada, (b) branqueada e (c) "in natura", à temperatura de 50,60 e $70{ }^{\circ} \mathrm{C}$ e pressão de $5 \mathrm{kPa}$

Estas figuras também mostram que a secagem das amostras de abóbora se realiza a velocidade de taxa decrescente durante a maior parte da secagem. Dados que bem a concordam com os obtidos por VACCAREZZA et al. (1974) para batata-doce e por MOWLAH et al. (1983) para bananas. Provavelmente o mecanismo físico que governa o movimento de umidade através da estrutura da cenoura e abóbora, é a difusão (MAZZA, 1983; KOMPANY et al., 1993). 


\section{2 - Efeito dos pré-tratamentos sobre a cenoura e abóbora}

As Figuras 3.3 e 3.4 mostram o efeito dos pré-tratamentos (congelamento e branqueamento) sobre a cinética de secagem da cenoura e abóbora respectivamente na pressão de 5,15 e $25 \mathrm{kPa}$ e temperatura de secagem de $60^{\circ} \mathrm{C}$. Através da Figuras 3.3 e 3.4 pode-se observar que as amostras

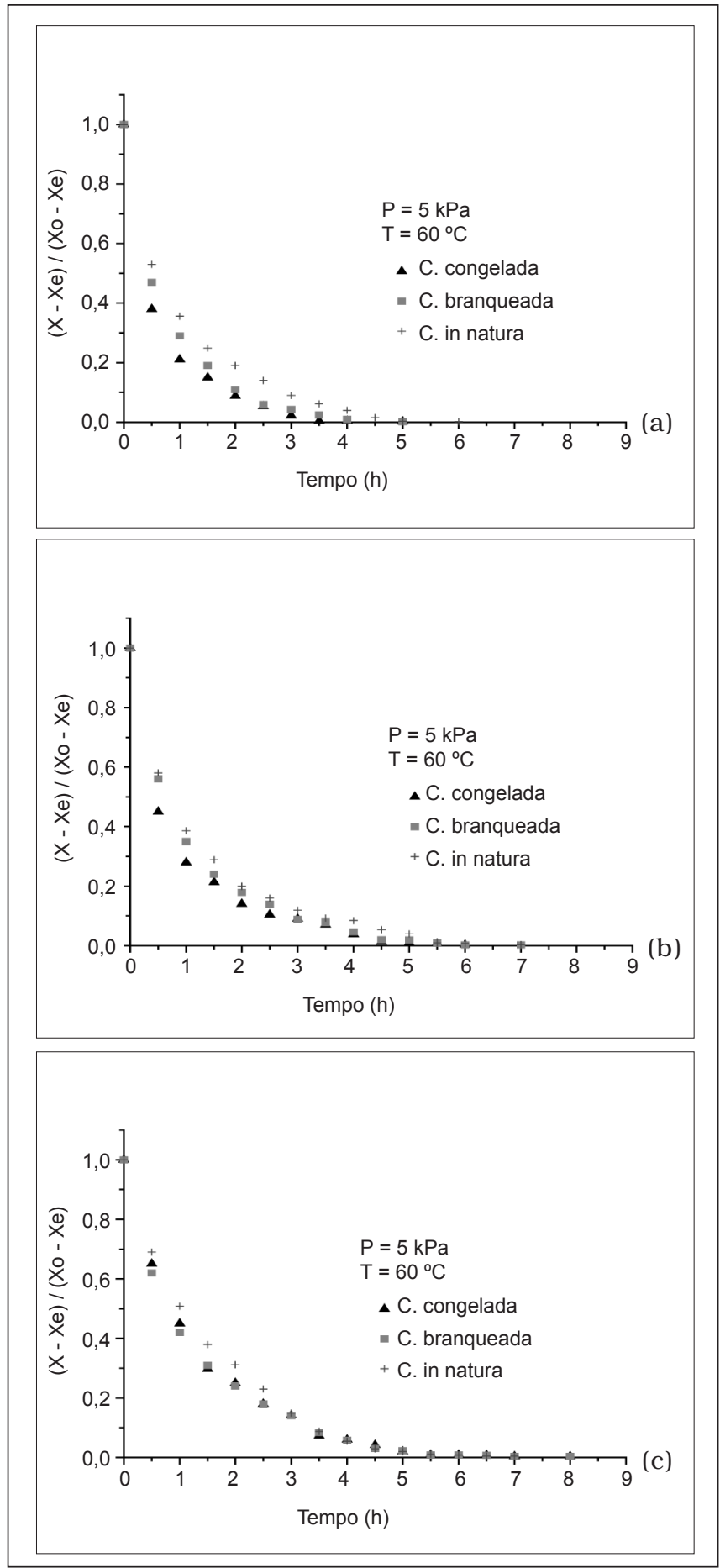

FIGURA 3.3 - Efeito dos pré-tratamentos sobre a cinética de secagem da cenoura a $60^{\circ} \mathrm{C}$ nas pressões de: (a) $5 \mathrm{kPa}$, (b) $15 \mathrm{kPa}$ e (c) $25 \mathrm{kPa}$ pré-tratadas por congelamento e branqueamento tanto na cenoura como na abóbora apresentam uma maior velocidade de secagem quando comparadas com as amostras in natura, nas mesmas condições de temperatura e pressão, embora amostras congeladas mostrem maior velocidade de secagem que as branqueadas. Porém essa influência dos pré-tratamentos diminui à medida que pressão aumenta como nota-se nas figuras quando a pressão é de 15 e $25 \mathrm{kPa}$,
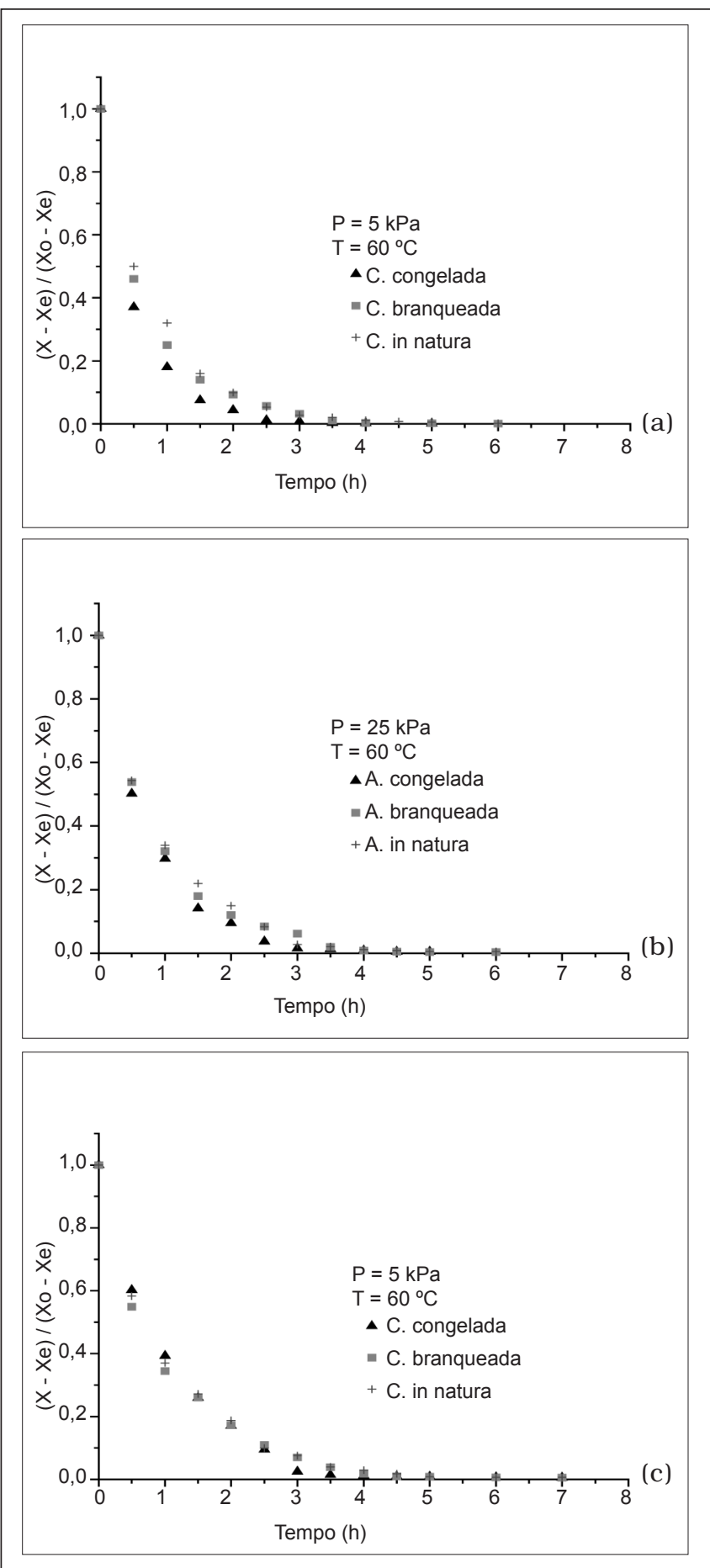

FIGURA 3.4 - Efeito dos pré-tratamentos sobre a cinética de secagem da abóbora a $60^{\circ} \mathrm{C}$ e nas pressões de: (a) $5 \mathrm{kPa}$, (b) $15 \mathrm{kPa}$ e (c) $25 \mathrm{kPa}$. 
onde as três curvas estão muito próximas indicando que os efeitos dos pré-tratamentos tornam-se menos acentuados quando a pressão aumenta.

Quanto ao tipo de matéria-prima o congelamento tem maior influência na velocidade de secagem nas amostras de abóbora que na cenoura para todos os casos estudados. O tempo de secagem da abóbora congelada na pressão de $5 \mathrm{kPa}$ é de aproximadamente 2,5 horas sendo que para cenoura é de 3,5 horas.

Tanto na cenoura quanto na abóbora, a maior velocidade de secagem foi observada nas amostras pré-tratadas por congelamento e secas a temperatura de $70^{\circ} \mathrm{C}$ e pressão de $5 \mathrm{kPa}$. Um comportamento semelhante foi observado por MAZZA (1983) durante o estudo da secagem com ar quente de cenoura pré-tratada por congelamento e por branqueamento. Porém este autor observou que existe uma maior influência do branqueamento, do que o congelamento, na velocidade de secagem e na qualidade do produto final. Conforme KOMPANY et al. (1990) esta maior velocidade de secagem observada nas amostras pré-tratadas deve-se ao fato do congelamento e branqueamento modificarem favoravelmente a estrutura inicial da matéria-prima melhorando a transferência de umidade e aumentando a velocidade de secagem.

De acordo com MAZZA (1983) o branqueamento é considerado como um tratamento que afeta a velocidade de secagem. Estes autores acreditam que os aspectos responsáveis pelo efeito do branqueamento são: mudanças nas propriedades físicas dos tecidos, assim como a destruição da membrana celular pelo aquecimento como mostram também o trabalho de HALPIN e LEE (1987) e a perda dos sólidos solúveis estudados por VACAREZZA e CHIRIFE (1975) afetando a velocidade de secagem.

\section{3 - Modelo difusional para amostras de cenoura e abóbora}

Os valores da difusividade efetiva do modelo difusional, na forma da segunda lei de Fick, baseados na equação (2.2), foram calculados através do ajuste não linear aos dados experimentais obtidos, utilizando geometria de placa plana infinita. Os valores foram calculados através do ajuste não linear com o auxilio do software Statistica 5.0. Para analisar o ajuste do modelo difusivo aos dados experimentais foram construídos os gráficos ((X-Xe)/(Xo-Xe)) em função do tempo de secagem, em escalas monolog.

Através das Figuras 3.5 pode-se observar que o modelo difusivo apresentou um bom ajuste aos valores experimentais para as amostras de cenoura congelada, branqueada e in natura, sendo os melhores ajustes a temperatura de 60 e $70^{\circ} \mathrm{C}$. Os valores de difusividade efetiva encontrados estão apresentados nas Tabela 3.1. Nota-se que a equação de difusão se ajustou bem aos dados experimentais de secagem como mostram os valores de $\mathrm{R}^{2}$ e erros relativos. Através desta Tabela 3.1, pode-se observar também, que os valores da difusividade efetiva nos indicam que a temperatura e pressão influenciam na cinética de secagem do produto. Temperaturas mais elevadas e menores pressões apresentam maiores valores de difusividade. Percebe-se que o valor da difusividade foi afetado pelo tipo de pré-tratamento aplicado na matéria-prima. Encontrando-se maiores valores para cenoura congelada, seguida em forma decrescente da cenoura branqueada e da in natura. Isto nos indica que os prétratamentos como o congelamento e o branqueamento favorecem o processo de transferência de massa.

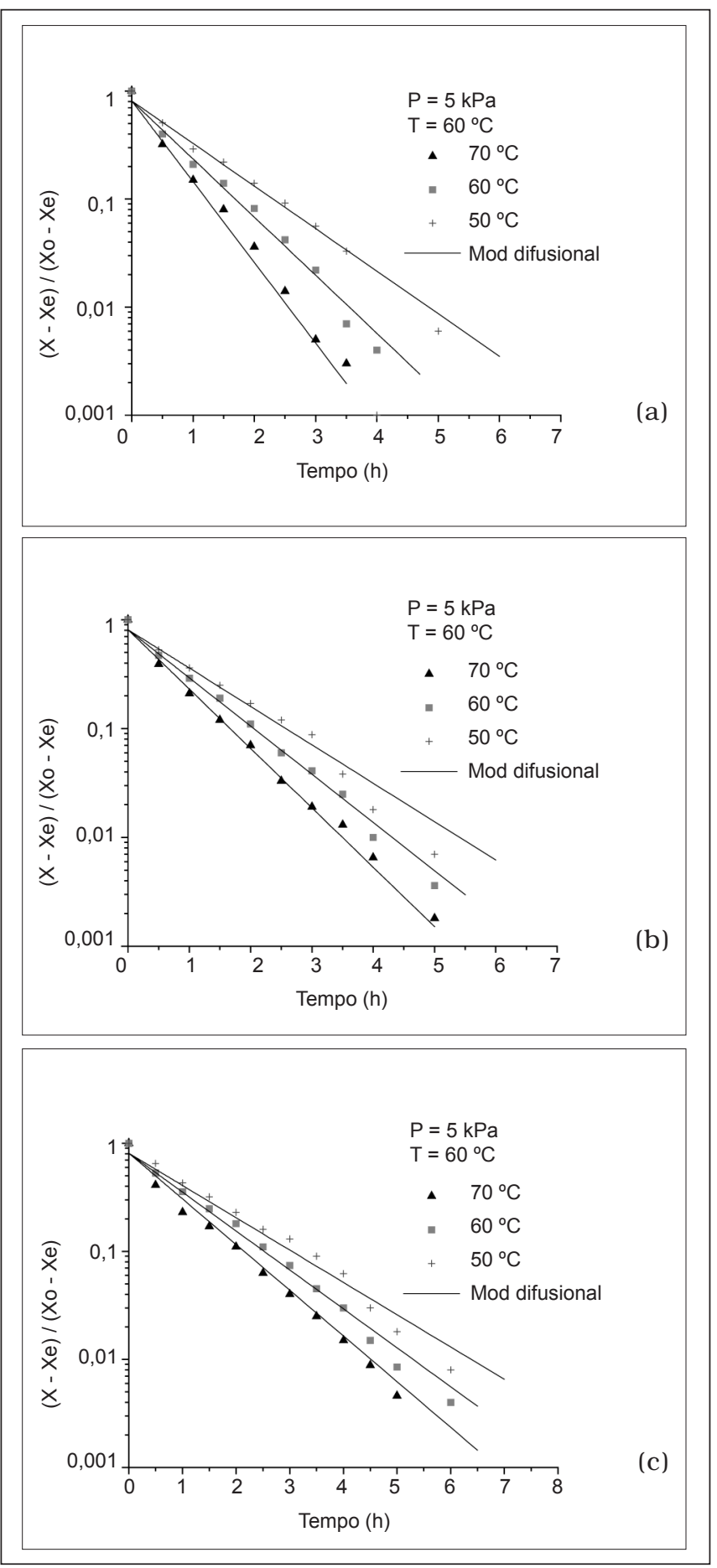

FIGURA 3.5 - Curvas de secagem de cenoura: (a) congelada, (b) branqueada e (c) in natura ajustadas pelo modelo difusional, à temperatura de 50,60 e $70^{\circ} \mathrm{C}$ e pressão de $5 \mathrm{kPa}$ 
Os valores de difusividade mostrada nas Tabelas mencionadas variam de 4,844 a $1,654 \times 10^{-9} \mathrm{~m}^{2} / \mathrm{s}$ para cenoura congelada; de 3,536 a $1,273 \times 10^{-9} \mathrm{~m}^{2} / \mathrm{s}$ para cenoura branqueada e de 2,740 a $1,469 \times 10^{-9} \mathrm{~m}^{2} / \mathrm{s}$ para cenoura "in natura". Pode-se notar que os maiores valores foram $4,844 \times 10^{-9}, 3,536 \times 10^{-9} \mathrm{e} 2,74 \times 10^{-9} \mathrm{~m}^{2} / \mathrm{s}$ respectivamente para cenoura congelada, branqueada e in natura, encontrados na temperatura de $70^{\circ} \mathrm{C}$ e pressão de $5 \mathrm{kPa}$. Estes valores são satisfatórios quando comparados com os dados da literatura, como os reportados por MULET et al. (1989) e MULET et al. (1983) entre 0,8 a $9,25 \times 10^{-9}$ $\mathrm{m}^{2} / \mathrm{s}$, estudando a secagem de cenoura à temperatura entre 30 a $70^{\circ} \mathrm{C}$ e KIRANOUDIS et al. (1995), que encontraram valores entre 1,5 e $4,5 \mathrm{~m}^{2} / \mathrm{s}$ para cenoura trabalhando a temperaturas entre 60 a $100^{\circ} \mathrm{C}$.

$\mathrm{O}$ ajuste do modelo difusional aos dados experimentais de abóbora congelada, branqueada e "in natura" estão mostrados na Figura 3.6. Da mesma forma como observado para cenoura, aqui também, o ajuste do modelo aos dados experimentais é sempre melhor para valores de alta temperatura e menores pressões de secagem tanto para abóbora congelada, branqueada e in natura.

Na Tabela 3.2 são apresentados os valores obtidos para a difusividade efetiva para as amostras de abóbora congelada, branqueada e in natura respectivamente, calculados por ajuste não linear das curvas de secagem ao modelo de difusão sem considerar o encolhimento da amostra. Tal como observado nas amostras de cenoura, a equação de difusão mostra um bom ajuste aos dados experimentais de secagem, pois tem-se altos valores do coeficiente de correlação $\mathrm{R}^{2}$ e baixos valores do erro relativo.

Através da Tabela 3.2, observa-se que os valores da difusividade efetiva indicam que a temperatura e pressão também influenciam na cinética de secagem da abóbora. Percebe-se que o valor da difusividade foi afetado pela temperatura e pressão de secagem e pelo tipo de prétratamento aplicado à matéria-prima. Os maiores valores foram encontrados para amostras de abóbora congelada, seguidos em forma decrescente da abóbora branqueada e da in natura. Isto indica que, além da temperatura e pressão, os pré-tratamentos como o congelamento e o branqueamento favorecem o processo de transferência de massa e, conseqüentemente, o aumento da difusividade.
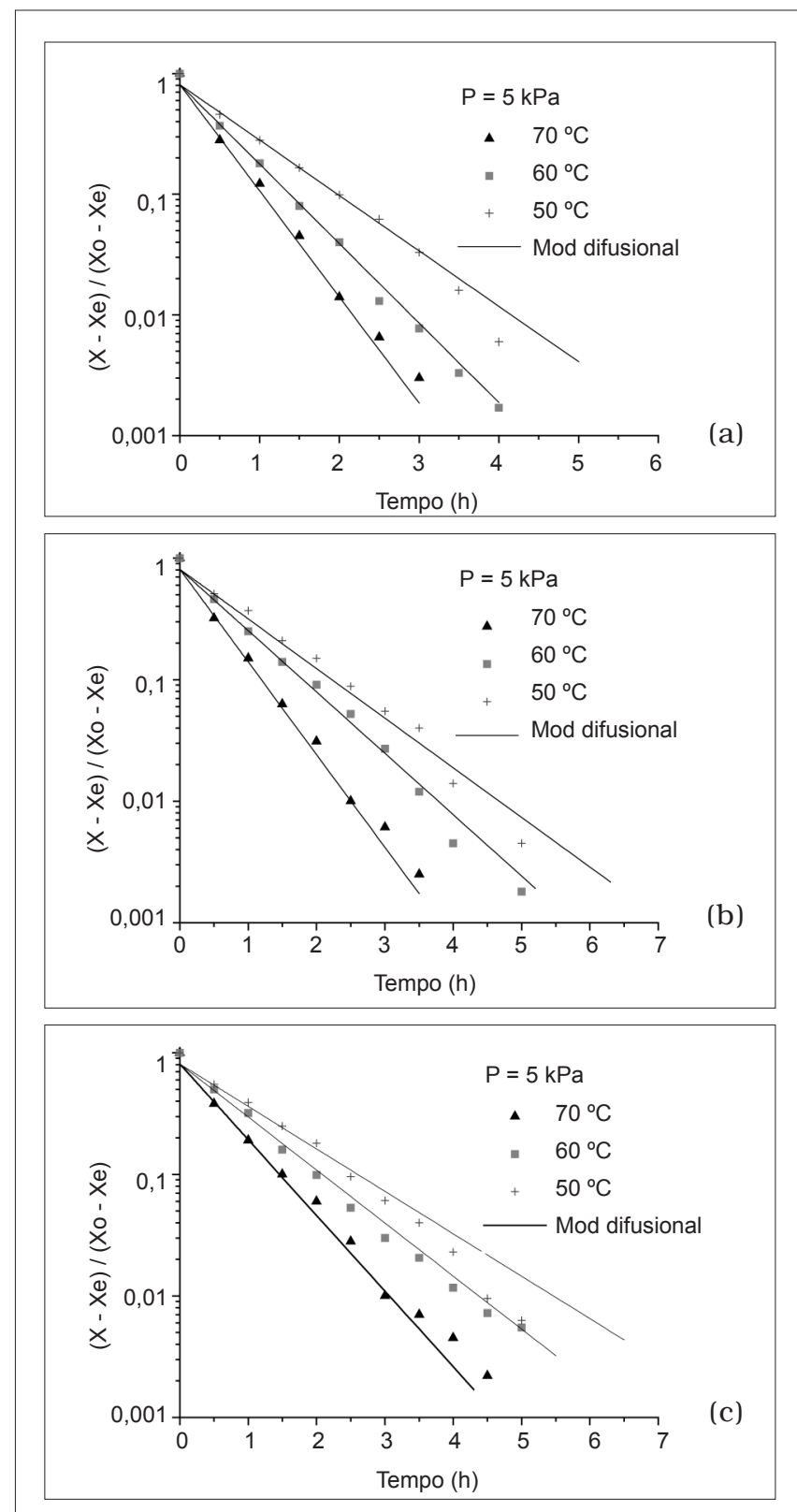

FIGURA 3.6 - Curvas de secagem de abóbora: (a) congelada, (b) branqueada e (c) in natura ajustadas pelo modelo difusional, à temperatura de 50,60 e $70^{\circ} \mathrm{C}$ e pressão de $5 \mathrm{kPa}$

TABELA 3.1 - Difusividade efetiva calculada pelo modelo difusional de cenoura congelada, branqueada e in natura nas diferentes condições de secagem

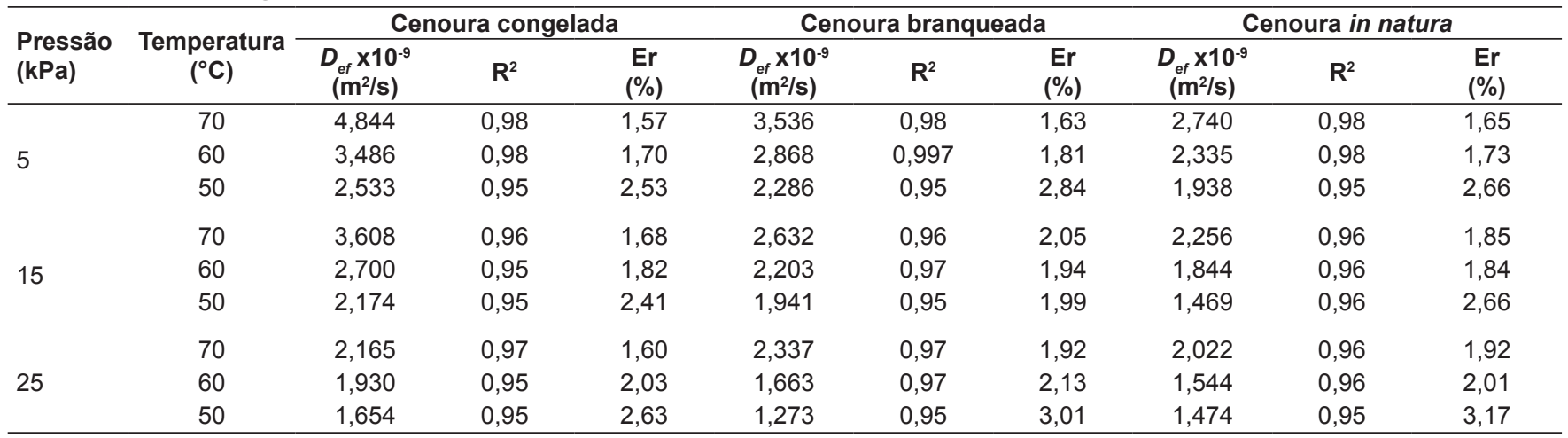


TABELA 3.2 - Valores da difusividade efetiva calculada pelo modelo difusional de abóbora congelada, branqueada e in natura nas diferentes condições de secagem

\begin{tabular}{|c|c|c|c|c|c|c|c|c|c|c|}
\hline \multirow[b]{2}{*}{ Pressão (kPa) } & \multirow[b]{2}{*}{$\begin{array}{c}\text { Temperatura } \\
\left({ }^{\circ} \mathrm{C}\right)\end{array}$} & \multicolumn{3}{|c|}{ Abóbora congelada } & \multicolumn{3}{|c|}{ Abóbora branqueada } & \multicolumn{3}{|c|}{ Abóbora in natura } \\
\hline & & $\begin{array}{c}D_{\text {ef }} \times 10^{-9} \\
\left(\mathrm{~m}^{2} / \mathrm{s}\right)\end{array}$ & $\mathbf{R}^{2}$ & $\begin{array}{c}\mathrm{Er} \\
(\%)\end{array}$ & $\begin{array}{c}D_{\text {ef }} \times 10^{-9} \\
\left(\mathrm{~m}^{2} / \mathrm{s}\right)\end{array}$ & $\mathbf{R}^{2}$ & $\begin{array}{l}\mathrm{Er} \\
(\%)\end{array}$ & $\begin{array}{c}D_{\text {ef }} \times 10^{-9} \\
\left(\mathrm{~m}^{2} / \mathrm{s}\right)\end{array}$ & $\mathbf{R}^{2}$ & $\begin{array}{c}\text { Er } \\
(\%)\end{array}$ \\
\hline \multirow{2}{*}{5} & 70 & 5,700 & 0,97 & 1,49 & 4,941 & 0,98 & 1,66 & 4,036 & 0,98 & 1,79 \\
\hline & 50 & 2,977 & 0,96 & 2,81 & 2,648 & 0,96 & 2,77 & 2,263 & 0,96 & 2,85 \\
\hline 15 & 70 & 3,525 & 0,97 & 1,90 & 3,220 & 0,98 & 1,55 & 3,125 & 0,97 & 1,86 \\
\hline \multirow{3}{*}{25} & 70 & 3,030 & 0,97 & 1,91 & 2,786 & 0,97 & 1,72 & 2,833 & 0,97 & 1,55 \\
\hline & 60 & 2,330 & 0,96 & 2,83 & 2,250 & 0,96 & 1,81 & 2,169 & 0,96 & 1,81 \\
\hline & 50 & 2,011 & 0,96 & 2,97 & 2,033 & 0,95 & 2,82 & 2,080 & 0,96 & 1,76 \\
\hline
\end{tabular}

Porém, na secagem da abóbora, os valores encontrados da difusividade são sempre maiores que na secagem de cenoura se comparados nas mesmas condições de processo. Assim, o valor encontrado para cenoura congelada a $70^{\circ} \mathrm{C}$ e $5 \mathrm{kPa}$ é de $4,844 \times 10^{-9} \mathrm{~m}^{2} / \mathrm{s}$, sendo que para abóbora nestas mesmas condições é de $5,70 \mathrm{~m}^{2} / \mathrm{s}$. Os valores de difusividade efetiva calculados estão na faixa de 5,70 a $2,011 \times 10^{-9} \mathrm{~m}^{2} / \mathrm{s}$ para abóbora congelada, de 4,941 a $2,033 \times 10^{-9} \mathrm{~m}^{2} / \mathrm{s}$ para abóbora branqueada e de 4,036 a $2,080 \times 10^{-9} \mathrm{~m}^{2} / \mathrm{s}$ para abóbora in natura.

Pode-se verificar que os valores da difusividade são da ordem de $10^{-9} \mathrm{~m}^{2} / \mathrm{s}$ e estão dentro da faixa reportada na literatura para secagem de diferentes tipos de vegetais. Não foi encontrado na literatura trabalho relacionado com a difusividade efetiva durante a secagem de abóbora. Para a batata, KIRANOUDIS et al. (1995) encontraram valores 1,0 a $5,3 \mathrm{~m}^{2} / \mathrm{s}$ para temperaturas entre 60 a $100^{\circ} \mathrm{C}$ e ALZAMORA e CHIRIFE (1980), o valor de $1,4 \mathrm{x}$ $10^{-9} \mathrm{~m}^{2} / \mathrm{s}$. à temperatura de $65^{\circ} \mathrm{C}$. Para a maçã, LUYBEN et al. (1980) encontraram difusividades de 0,31 a 2,5 x $10^{-9} \mathrm{~m}^{2} / \mathrm{s}$ a temperaturas entre 30 a $60^{\circ} \mathrm{C}$.

\section{4 - CONCLUSÕES}

Para todos os ensaios experimentais, as amostras pré-tratadas por congelamento apresentam maiores velocidades de secagem quando comparadas às amostras branqueadas e às in natura, pois o congelamento da água modificou propriedades físicas como a porosidade da matéria-prima, favorecendo a secagem.

Os parâmetros de secagem dependeram da natureza da matéria-prima. Observa-se que as amostras de abóbora apresentam maiores velocidades de secagem que as de cenoura independentemente do tratamento recebido e da condição de secagem utilizada.

A utilização do modelo difusional da $2^{\text {a }}$ lei de Fick é excelente para ajustar as curvas de secagem. Os valores de difusividade efetiva sem considerar o encolhimento variam de: 4,844 a 1,654 x $10^{-9} \mathrm{~m}^{2} / \mathrm{s}, 3,536$ a $1,273 \times 10^{-9} \mathrm{~m}^{2} / \mathrm{s}$ e de 3,2555 a $1,2455 \times 10^{-9} \mathrm{~m}^{2} / \mathrm{s}$ para cenoura congelada, branqueada e in natura respectivamente. Para abóbora, de 5,70 a 2,011 × $10^{-9} \mathrm{~m}^{2} / \mathrm{s}, 4,941$ a $2,033 \times 10^{-9} \mathrm{~m}^{2} / \mathrm{s}$ e de 4,033 a $2,080 \times 10^{-9} \mathrm{~m}^{2} / \mathrm{s}$ congelada, branqueada e in natura, respectivamente. Esses valores de difusividade têm a mesma ordem de grandeza da maioria dos vegetais estudados na literatura.

\section{5 - REFERÊNCIAS BIBLIOGRÁFICAS}

[1] ARÉVALO-PINEDO, A. Secagem a vácuo de cenoura (Daucus carota) e abóbora (Cucúrbita máxima): Estudo das características do processo. Campinas, 2003. Tese de doutorado, Faculdade de Engenharia de Alimentos. Universidade Estadual de Campinas (UNICAMP), $173 \mathrm{p}$.

[2] ALZAMORA, S.M.; CHIRIFE J. Some factors controlling the kinetics of moisture movement during avocado dehydration. Journal of Food Science, v. 45, p. 1649$1651,1980$.

[3] BROOKER, D.B.; BAKKER-ARKEMA, F.W.; HALL, C.W. Drying Cereal Grains. Connecticut, The AVI Publishing Company, Inc, 1974.

[4] CRANK, J. The Mathematics of Diffusion. $2^{\text {nd }}$ ed., Claredon Press, p. 114, 1975.

[5] HALPIN, B.E.; LEE, C.Y. Effect of blanching on enzyme activity and quality changes in green peas. Journal of Food Science, v. 52, n 4, p. 1002-1005, 1987.

[6] KIRANOUDIS, C.T.; MAUROLIS, Z.B.; MARINOS-KOURIS, D. Mass transfer model building in drying. Drying Technology, v. 11, n. 6, p. 1251-1270, 1993.

[7] KROKIDA, M.K.; ZOGZAS, N.P; MAROULIS, Z.B. Modeling shrinkage and porosity during vacuum dehydration. International Journal of Food Science and Technology, v. 32, p. 445-458, 1997.

[8] KOMPANY, E.; BENCHIMOL, J.; ALLAF, K.; AINSEBA, B.; BOUVIER, J.M. Carrot dehydration for instant rehydration: dehydration kinetics and modeling. Drying Technology, v. 11, n. 3, p. 451-470, 1993.

[9] KOMPANY, E.; ALLAF, K.; BOUVIER, J.M.; GUIGON, P.; MAUREAUX, A. Nouveau procédé de déshydratation des fruits et legumes à réhydration instantanée. Industries Alimentaires et Agricoles, p. 1243-1248, 1990.

[10] LUYBEN, K.C.; OLIMAN, M.A.C.; BRUIN, S. In: Drying 80, v. 2, p. 233-243, editora A.S. Mujumdar, Hemisphere Publishing Corporation, Washington, 1980. 
[11] MAZZA, G. Dehydration of carrots: Effects of predrying treatments on moisture transport and product quality. Journal of Food Technology, v. 18, p. 113-123, 1983.

[12] MOWLAH, G.; TAKANO, K.; KAMOI, I. e OBARA, T. Water transport mechanism and some aspects of quality changes during air dehydration of bananas. Lebensmittel-Wissenschaft und Technologie, v. 16, n. 2, p.103-107, 1983.

[13] MULET, A.; BERNA, A.; ROSELlO, C. Drying of car- rots I. Drying Models. Drying Technology, v. 7, n. 3, p.537-557, 1989.

[14] MULET, A.; ROSELlÓ, C.; PIÑAGA, F.; CARBONEL, J.V.; BERNA, A. Mecanismo e cinética del secado de zanahorias com aire caliente. Revista de Agroquímica y Tecnología de Alimentos, v. 23, n. 3, p. 369-377, 1983.

[15] VACCAREZZA, L.; CHIRIFE, J. On the mechanism of moisture transport during air-drying of sugar beetroot. Journal of Food Science, p. 1286-1289, 1974. 